\title{
BMJ Open Effects of different amounts of exercise on preventing depressive symptoms in community-dwelling older adults: a prospective cohort study in Taiwan
}

Yu-Chen Chang, ${ }^{1}$ Mei-Chun Lu, ${ }^{2}$ I-Han Hu, ${ }^{3}$ Wan-Chi Ida Wu, Susan $\mathrm{C} \mathrm{Hu}{ }^{4}$

To cite: Chang Y-C, Lu M-C, $\mathrm{Hu} \mathrm{I}-\mathrm{H}$, et al. Effects of different amounts of exercise on preventing depressive symptoms in communitydwelling older adults: a prospective cohort study in Taiwan. BMJ Open 2017;7:e014256. doi:10.1136/ bmjopen-2016-014256

- Prepublication history and additional material are available. To view please visit the journal (http://dx.doi.org/ 10.1136/ bmjopen-2016-014256)

Received 13 September 2016 Revised 26 February 2017 Accepted 21 March 2017

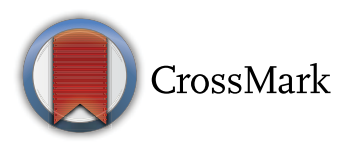

${ }^{1}$ Department of Community Health, Ditmanson Medical Foundation Chia-Yi Christian Hospital, Chia-Yi City, Taiwan ${ }^{2}$ Department of Medical Research, Kuang Tien General Hospital, Taichung, Taiwan ${ }^{3}$ Institute of Gerontology, National Cheng Kung University College of Medicine, Tainan,

Taiwan

${ }^{4}$ Department of Public Health, National Cheng Kung University College of Medicine, Tainan, Taiwan

Correspondence to

Dr Susan C Hu;

shuhu@mail.ncku.edu.tw

\section{ABSTRACT}

Objectives To compare the effects of four different amounts of exercise for preventing depressive symptoms in community-dwelling older adults.

Design Prospective cohort study.

Setting A nationally representative sample in Taiwan. Participants Four waves of the survey 'Taiwan Longitudinal Study on Aging (TLSA)' from 1996 to 2007 were analysed. A total of 2673 older adults aged 65 years and over were recruited.

Primary and secondary outcome measures Depressive symptoms were measured using the Center for Epidemiologic Studies Depression Scale (CESD). Four different types/amounts of exercise were examined including: (1) 3 times/week, 15 min/time; (2) 3 times/ week, $30 \mathrm{~min} /$ time; (3) 6 times/week, $15 \mathrm{~min} / \mathrm{time}$; and (4) 6 times/week, $30 \mathrm{~min} /$ time. All exercise types were required to have at least moderate intensity. The impacts of different amounts of exercise on depressive symptoms were analysed using generalised linear mixed models. Results More than one-fifth of the elder individuals under consideration had depressive symptoms (CESD $\geq 10$ ). About $38.6 \%$ of older adults met the lowest criteria for exercise type 1, and fewer $(28.0 \%)$ met the highest criteria for type 4 . Only exercise type 4 in the current survey was initially related to lower depressive symptoms $(\mathrm{OR}=0.8,95 \% \mathrm{Cl} 0.66$ to 0.95$)$. However, after considering the interaction between time and changes in exercise patterns, the results showed that all persistent exercise models, even if a very low amount ( 3 times/week, $15 \mathrm{~min} /$ time), had significantly preventive effects on depressive symptoms $(\mathrm{OR}=0.56 \sim 0.67)$.

Conclusion Consistent exercise with at least $15 \mathrm{~min}$ per time, three times a week of moderate intensity is significantly associated with lower risk of depressive symptoms. This low amount of exercise may be easier to promote at the community and population level than other alternatives.

Trial registration Registry number 104040 of the Institutional Ethics Committee of Chia-Yi Christian Hospital.

\section{INTRODUCTION}

Late life depression is an important health issue among different ethnic groups, affecting $13.7 \%$ of the population in the USA and $20 \%$ of older Chinese adults in

\section{Strengths and limitations of this study}

This is the first report to compare the effects of four different amounts of exercise on preventing depressive symptoms in older adults.

- The strengths of this study include the fact that it is a nationally representative sample, a longitudinal cohort design, an examination of the changes in exercise status over time and a proper consideration of statistical analysis methods.

- However, the effects of different variables for depression may be altered for different cohorts because of changes in medicine, nutrition or the environment.

- The outcome event was performed the same time as the second visit to develop the changes in exercise patterns, which may reduce the interpretation of a causal relationship.

Taiwan. ${ }^{12}$ Depressive disorder has been indicated as one of the top 10 causes of years lived with disability among 188 countries based on the Global Burden of Disease Study, 2013. ${ }^{3}$ It has also been closely linked to quality of life among community-dwelling older adults in many studies. ${ }^{4-6}$

Several relevant interventions have been suggested for preventing or treating depression in addition to medicine. For instance, having a marital partner or having good social support will significantly reduce the impacts of disability from depression. ${ }^{7}$ Psychological intervention, especially group based, has been shown to have benefits in regard to both prevention and economic effects. ${ }^{8-10}$ Six weeks of healthy dietary practice has also been helpful in reducing depressive symptoms, and the benefits may be sustained for as long as 2 years. ${ }^{11}$

However, even in ancient Greece, Hippocrates suggested that his patients exercise to treat the behaviours of overconsumption, and Galen further instructed patients to exercise to reduce troublesome depression. ${ }^{12}$ Many 
mechanisms of antidepressive effects of exercise were summarised in Rethorst, Wipfli and Landers's study. ${ }^{13}$ For example, four mechanisms in hippocampal neurogenesis can be potentially facilitated by exercise: increases in B-endorphins, vascular endothelial growth factor, brain-derived neurotrophic factor and serotonin. Thus, exercise is potentially an effective approach to treating or preventing depression.

Little research has focused on the relationship between exercise and depressive symptoms in the elderly. Among the limited number of studies, exercise seems to have similar effects to those of some pharmacological treatments, ${ }^{14}$ but some meta-analysis studies have yielded inconsistent results. ${ }^{15-17}$ Also, exercise did not always show benefits related to preventing or treating depression because many of the studies did not control for previous levels of depressive symptoms, and only a few included a follow-up period of more than 2 years. Furthermore, since exercise status changes as people age, how the transitional patterns of exercise in older adults affect depressive symptoms has yet to be studied.

In addition, in the case of older adults, exercise programmes must consider both intensity and duration. The general recommendation for exercise by the American College of Sports Medicine is moderate intensity; exercise is engaged in at least $30 \mathrm{~min}$ per day at least 5 days a week to accumulate a total of 150-300 min per week, or vigorous intensity of at least $20 \mathrm{~min}$ per day for $3-5$ days per week to a total of $75-100 \mathrm{~min} /$ week. ${ }^{18}$ However, a recent study by Wen $e t$ al indicated that a low amount of exercise, which is defined as $15 \mathrm{~min}$ per day or $90 \mathrm{~min}$ per week at moderate intensity, has proven beneficial in reducing all-cause and all-cancer mortality. ${ }^{19}$ This result provides a more age-friendly exercise model, which could be further explored in regard to its effects on depressive symptoms in older adults.

Therefore, in this study, we use an 11-year cohort data from a population-based survey to examine how different amounts of exercise affect depressive symptoms in older adults. The purposes of the study were: (1) to examine the impacts of four different types of exercise on preventing depressive symptoms in older adults using Taiwan as an example and (2) to test the effects of changes in exercise status during a specific period of time on depressive symptoms in the elderly.

\section{METHODS}

\section{Study design and participants}

This is a longitudinal cohort study, using nationally representative data from the survey 'Taiwan Longitudinal Study on Aging, TLSA'. The TLSA survey was undertaken as a collaborative project between the University of Michigan, USA, and the Health Promotion Administration, Ministry of Health and Welfare, Taiwan. There were six waves of surveys for those aged 60 years and over in 1989, 1993, 1996, 1999, 2003 and 2007. Supplemental cases aged 50 years and older were added to the cohort in 1996 and 2003. A three-stage proportional-to-size probability sampling technique was used in the survey, and face-toface interviews were conducted with each individual. The response rates in each wave were high, ranging from $81.2 \%$ to $91.4 \%$.

Since detailed exercise questionnaires were launched in 1996, we combined two cohorts (cohort B aged 67+ years and cohort A aged 50-66 years) in 1996 as our study cohort. The inclusion criterion was aged 65 years and older; the exclusion criteria included those who did not complete the relevant questionnaires, lived in institutions or answered by proxy. We used the 1999 survey as the baseline and followed subjects up to 2007. A total of 2673 valid participants was selected as the baseline, and 5923 observations were counted.

Due to the significant effects of previous depressive symptoms and changes in exercise behaviour on depression, we used more retrospective data as control variables from the 1996 survey when analysing the effects in 1999. Thus, the total number of observations in the four-wave surveys was 8397 . The flow chart of the valid sample size is shown in figure 1 . This study was approved by the Institutional Ethics Committee of Chia-Yi Christian Hospital (registry number 104040).

\section{Measurements}

\section{Dependent variable: depressive symptoms}

Depressive symptoms were measured with the Center for Epidemiologic Studies Depression Scale (CESD). This 20 -item scale assessment ${ }^{20}$ was modified to a 10-item scale, ${ }^{21}$ which was used in the TLSA survey. Each item was scored from 0 to 3, making the total score range from 0 to 30 . The measure, with a cut-off score of 10 , has been recommended as a good tool to assess depressive symptom severity at the community level. ${ }^{22}$ Because level of depressive symptoms is associated with future depression and quality of life, ${ }^{23} 24$ we categorised the level of depressive symptoms into no depressive symptom, defined as $\mathrm{CESD}=0$; lower level of depressive symptoms (LLDSs), $0<\mathrm{CESD} \leq 9$; and higher level of depressive symptoms (HLDSs), CESD $\geq 10$.

\section{Independent variables: types/amount of exercise and changing patterns}

The degree of exercise was quantified by asking about the frequency $(0, \leq 2,3-5, \geq 6$ times per week), duration $(<15 \mathrm{~min}, 15-30 \mathrm{~min},>30 \mathrm{~min})$ and intensity based on sweating level (none, a little, a lot and none of the above) and panting level (none, a little, a lot and none of the above) after exercise.

Four types/amount of exercise were classified in this study. Exercise type 1 means that exercise of at least moderate intensity was performed $\geq 3$ times/week, $\geq 15 \mathrm{~min} /$ time (T3_15); exercise type 2 means $\geq 3$ times/ week, $>30 \mathrm{~min} /$ time (T3_30); exercise type 3 means $\geq 6$ times/week, $\geq 15 \mathrm{~min} /$ time (T6_15); and exercise type 4 means $\geq 6$ times/week, $>30 \mathrm{~min} /$ time (T6_30). Moderate intensity was defined as experiencing some sweating and panting after exercise. ${ }^{18}$ 
Cohort B

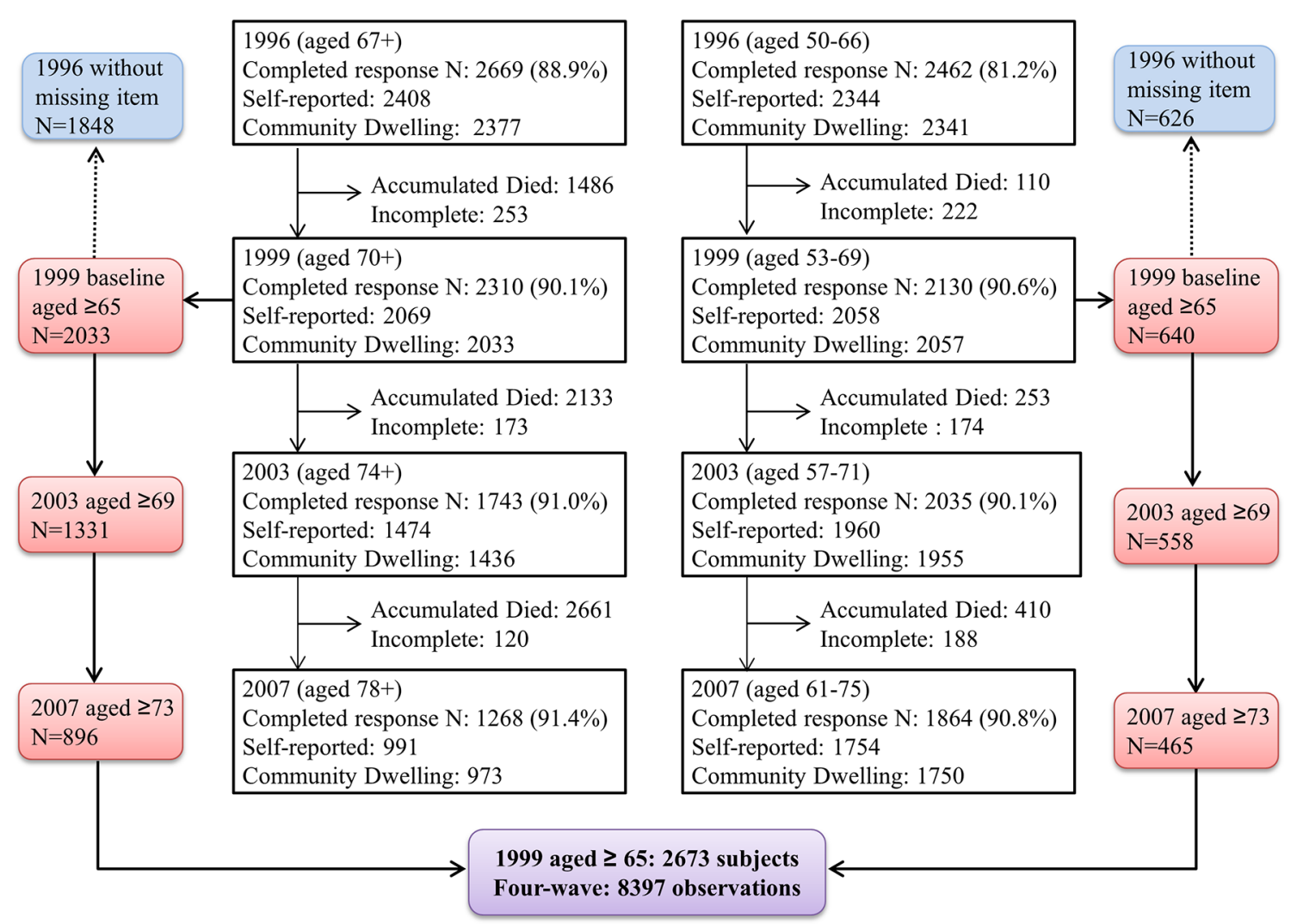

Figure 1 Number of participants in the four-wave surveys.

Patterns of exercise consistency refers to changes in the practice of respective exercise types between two waves, which was classified as: (A) low pattern (pattern $\mathrm{NN}$ ): the respective exercise type was not practiced in the previous or in the current surveys; (B) declining pattern (pattern $\mathrm{YN})$ : the respective exercise type was practiced in the previous but not in the current surveys; (C) increasing pattern (pattern NY): the respective exercise type was practiced in the current but not in the previous surveys; and (D) persistent pattern (pattern YY): the respective exercise type was practiced in both the previous and in the current surveys. In the analysis, all models were based on paired observations between two waves, for example, 1996-1999, 1999-2003 and 2003-2007. Therefore, when someone exercised in 2003 and 2007 but not 1999, he/ she was counted twice, as 'increasing pattern' in 19992003 and as 'persistent pattern' in 2003-2007.

\section{Control variables}

Sociodemographic variables included gender, age, marital status (married or living with a partner was coded as 1, otherwise 0 ), level of education (none, elementary, junior high school, senior high school and college and above), economic satisfaction (dissatisfied and satisfied) and employment status (yes/no).

Physical function involved reversing the scale of a 4-point measurement inquiring the level of difficulty of seven mobility tasks, including standing for $15 \mathrm{~min}$, squatting, raising both arms up, grasping with fingers, lifting an $11 \mathrm{~kg}$ weight, running 20-30 $\mathrm{m}$ and climbing up two to three floors. The sum of the physical battery ranged from 0 to 21. A higher score indicated a better physical battery. These measurements have been reported as hierarchically associated with instrumental and basic activities of daily living. ${ }^{25}$

Social participation refers to participation in any of the following groups: volunteers, community groups, religious groups, occupational associations, political parties or groups, social service groups, clan associations, senior groups or schools. Social participation was coded as a binary variable (yes/no).

Emotional support was the summed scores of seven items, which were coded from 0 to 3 , including (1) family/relatives/friends care about you; (2) family/relatives/friends listen to you; (3) you can count on family/ relatives/friends when you are ill; (4) you are satisfied with the support from your family/relatives/friends; (5) how often do your family or friends come to you for opinions?; (6) in what ways do you feel that you are helpful to your family or friends?; and (7) how often do you feel rejected by your family/relatives/friends? The last item was scored reversely.

Health-related variables included self-rated health (poor, fair and good) and other binary variables such as current smoking and 10 chronic conditions including 
cancer, chronic respiratory disease, gastrointestinal disease, hypertension, diabetes mellitus, heart disease, stroke, arthritis, hepatobiliary disease and renal disease.

\section{Statistical analysis}

The descriptive analysis of depressive symptoms and covariates were presented as a mean $\pm \mathrm{SD}$ or as $\mathrm{n}(\%)$ for continuous or categorical data, respectively. We applied generalised linear mixed models via PROC GLIMMIX to estimate the effects of different transitional patterns of exercise on depressive symptoms with HLDS as the event, after adjusting for the previous CESD score, age, gender, level of education, marital status, smoking, physical function, emotional support, social participation, self-rated health, economic satisfaction, employment and 10 chronic conditions. The interaction of time and transitional patterns of exercise was also included in the above analysis. A two-sided $p$ value $<0.05$ was considered statistically significant. All data were merged and analysed using SAS V.9.2 (SAS Institute, Cary, North Carolina, USA).

\section{RESULTS}

There were 2673 valid subjects selected from the survey conducted in 1999, and a total of 8397 observations in four survey waves. Table 1 shows the distribution of characteristics for the subjects from 1999 (baseline) to 2007. At baseline, the average age was $74.2 \pm 5.7$ years old, of which $54.5 \%$ were men. The prevalence of LLDS and HLDS was $20 \sim 24 \%$ over time. About $38.6 \%$ of participants met the lowest criteria of T3_15, and fewer (28.0\%) met the highest criteria of T6_30. Noticeably, in any survey, exercise models T3_15 and T6_15 have a higher proportion than T3_30 and T6_30. This may imply the difficulty for older adults to engage in long periods of exercise.

Table 2 illustrates the OR of HLDS according to the current practices of exercise models and other determining factors. Only exercise type 4 (T6_30) had a significant reducing effect on HLDS ( $\mathrm{OR}=0.80,95 \%$ CI 0.66 to 0.95). Also, the previous level of depressive symptoms, physical function, emotional support, selfrated health and economic satisfaction were all positively predictive of HLDS.

Table 3 shows the predictive effects of previous exercise models for higher levels of depressive symptoms. However, none of the four exercise models in the previous survey could predict the presence of higher levels of depressive symptoms. Namely, previous exercise behaviour appeared to have no benefits on reducing depression, regardless of the amount or type of exercise. This may suggest that the effects of exercise on depressive symptoms are only concurrent and short term.

Thus, we conducted another test to examine the effect of changes in different exercise models on depressive symptoms, as shown in table 4. After controlling for other determining factors and considering the interaction of time and patterns of exercise, the results indicated that only persistent patterns (pattern $\mathrm{YY}$ ) reveal a significant protective effect from higher levels of depressive symptoms, regardless of exercise type $(\mathrm{OR}=0.58,0.56,0.67$, 0.62 , respectively, all $\mathrm{p}<0.05)$. Namely, even the lower amount of exercise (T3_15) may have protective effects on depression as long as older adults continuously reach moderate intensity for at least $15 \mathrm{~min}$ with a frequency of no less than three times a week.

\section{DISCUSSION}

Very limited research has been conducted to determine the long-term effects of different exercise models on depressive symptoms in the elderly. The purpose of the current study was to examine the impacts of four different types of exercise on depressive symptoms in community-dwelling older adults. We found that only current exercise type 4 (T6_30) was significantly associated with lower depressive symptoms, whereas previous exercise behaviour seemed to have no benefits with regard to reducing depression. However, when considering the changes in exercise behaviour between two waves, this study shows that different patterns of exercise are significantly associated with HLDS outcomes. Only the persistent patterns of exercise (pattern YY) revealed a significant protective effect from higher levels of depressive symptoms.

Furthermore, this study shows that persistent low-volume exercise, that is, $\geq 15 \mathrm{~min}$ of moderate intensity exercise (T3_15 and T6_15), can provide preventive effects on depressive symptoms, similar to the benefits of high-volume exercise, that is, $\geq 30 \mathrm{~min}$ of moderate intensity exercise (T3_30 and T6_30), in older adults. These findings suggest that short, age-friendly exercise types may benefit older adults both physically and psychologically.

Comparing similar studies from $\mathrm{Ku}$ et al, where they suggested that exercise frequency may be important for depressive symptoms ${ }^{26}$ and where the changing pattern of the low-low group led to a high risk of developing depressive symtoms, ${ }^{27}$ our study revealed that consistency may be the key factor, regardless the frequency or duration of exercise, as long as the exercise is of moderate intensity. Namely, both exercise frequencies of $\geq 3$ times/ week or $\geq 6$ times/week with at least $15 \mathrm{~min}$ or $30 \mathrm{~min}$ each time showed significantly negative association with higher levels of depressive symptoms in this study. These results indicate the importance of the consistency of exercise.

Noticeably, the study by Ku et al analysed only traditional types of physical activity according to frequency, while in this study, we compared four types of physical activity and measured physical activity simultaneously by using three dimensions, including frequency, duration and intensity. In addition, we considered important covariates related to depressive symptoms, such as social participation, emotional support, mobility and self-rated health, among others. Therefore, we believe our results can substantially contribute to the existing knowledge of the relationship between physical activity and depressive symptoms. 
Table 1 Characteristics of the participants from 1999 to 2007

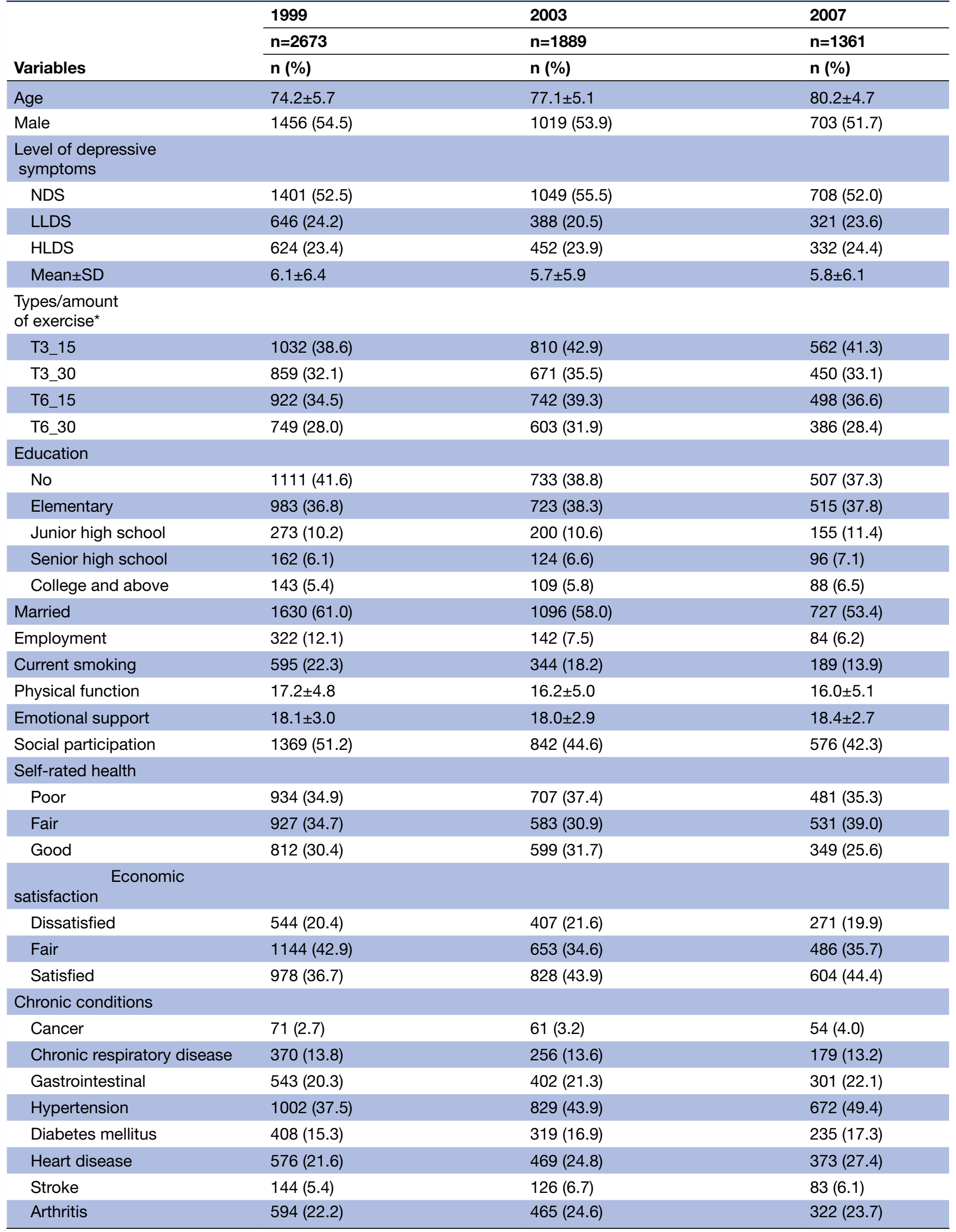


Table 1 Continued

\begin{tabular}{llll} 
& $\mathbf{1 9 9 9}$ & $\mathbf{2 0 0 3}$ & $\mathbf{2 0 0 7}$ \\
\cline { 2 - 4 } Variables & $\mathbf{n = 2 6 7 3}$ & $\mathbf{n = 1 8 8 9}$ & $\mathbf{n = 1 3 6 1}$ \\
\cline { 2 - 4 } & $\mathbf{n}(\mathbf{\%})$ & $\mathbf{n}(\mathbf{\%})$ & $\mathbf{n}(\mathbf{\%})$ \\
\hline Hepatobiliary disease & $191(7.2)$ & $158(8.4)$ & $116(8.5)$ \\
Renal disease & $217(8.1)$ & $192(10.2)$ & $139(10.2)$ \\
\hline
\end{tabular}

Data were presented as mean \pm SD or $\mathrm{n}(\%)$.

*T3_15: exercise $\geqq$ moderate intensity, $\geqq 3$ times/week, $\geqq 15 \mathrm{~min} /$ time; T3_30: exercise $\geqq$ moderate intensity, $\geqq 3$ times/week, $\geqq 30 \mathrm{~min} / \mathrm{time}$; T6_15: exercise $\geqq$ moderate intensity, $\geqq 6$ times/week, $\geqq 15 \mathrm{~min} /$ time; T6_30: exercise $\geqq$ moderate intensity, $\geqq 6$ times/week, $\geqq 30 \mathrm{~min} / \mathrm{time}$. CESD, Center for Epidemiologic Studies of Depression; HLDS, higher level of depressive symptoms (CESD $\geqq 10$ ); LLDS, lower level of depressive symptoms $(0<\mathrm{CESD} \leqq 9)$; NDS, no depressive symptom $(C E S D=0)$.

Another study using a Taiwanese national survey suggested promoting high intensity, rather than frequent or long duration exercise, to improve mental well-being in older adults, ${ }^{28}$ the results of which are not completely compatible with our findings. However, the nature of the cross-sectional study design used in that study may have caused it to have a higher possibility of overinterpretation of the results. Less depressed people may be more likely to engage in higher intensity exercise as compared with more depressed people. Our longitudinal study suggests that a low amount of exercise also has benefits related to preventing depressive symptoms. Furthermore, transitional patterns of exercise may be more important than the current exercise models that people are practicing.

Physical inactivity was found to be among the top 10 leading risk factors for the global disease burden in

Table 2 ORs of HLDS according to the current exercise behaviour as estimated using GLMM*

\begin{tabular}{|c|c|c|}
\hline \multirow[b]{2}{*}{ Variables } & \multicolumn{2}{|l|}{ HLDS } \\
\hline & OR (95\% Cl) & p Value \\
\hline \multicolumn{3}{|c|}{ Types/amount of exercise } \\
\hline T3_30 & $0.86(0.59$ to 1.25$)$ & 0.42 \\
\hline T6_15 & 0.86 (0.65 to 1.13$)$ & 0.27 \\
\hline \multicolumn{3}{|c|}{ Previous level of depressive symptoms } \\
\hline NDS & ref & \\
\hline LLDS & 1.83 (1.48 to 2.28$)$ & $<0.001$ \\
\hline HLDS & 3.04 (2.39 to 3.85$)$ & $<0.001$ \\
\hline Physical function & 0.92 (0.90 to 0.93$)$ & $<0.001$ \\
\hline Poor & ref & \\
\hline Fair & $0.52(0.44$ to 0.61$)$ & $<0.001$ \\
\hline Good & 0.29 (0.23 to 0.36$)$ & $<0.001$ \\
\hline \multicolumn{3}{|c|}{ Economic satisfaction } \\
\hline Dissatisfied & ref & \\
\hline Fair & 0.51 (0.43 to 0.60$)$ & $<0.001$ \\
\hline Satisfied & $0.33(0.27$ to 0.40$)$ & $<0.001$ \\
\hline
\end{tabular}

T3_15: Exercise $\geq$ moderate intensity, $\geq 3$ times/week, $\geq 15 \mathrm{~min} /$ time.

T3_30:Exercise $\geq$ moderate intensity, $\geq 3$ times/week, $\geq 30 \mathrm{~min} /$ time.

T6_15: Exercise $\geq$ moderate intensity, $\geq 6$ times/week, $\geq 15 \mathrm{~min} /$ time.

T6_30: Exercise $\geq$ moderate intensity, $\geq 6$ times/week, $\geq 30 \mathrm{~min} /$ time.

${ }^{*}$ All of the analysis models were adjusted according to present age, gender, education, marital status, smoking, social participation and chronic conditions including cancer, chronic respiratory disease, gastrointestinal, hypertension, diabetes mellitus, heart disease, stroke, arthritis, hepatobiliary disease and renal disease.

HLDS, higher level of depressive symptoms (CESD $\geqq 10$ ); GLMM, generalised linear mixed models; LLDS, lower level of depressive symptoms; NDS, no depressive symptom. 
Table 3 ORs of HLDS according to the previous exercise behaviour as estimated by GLMM*

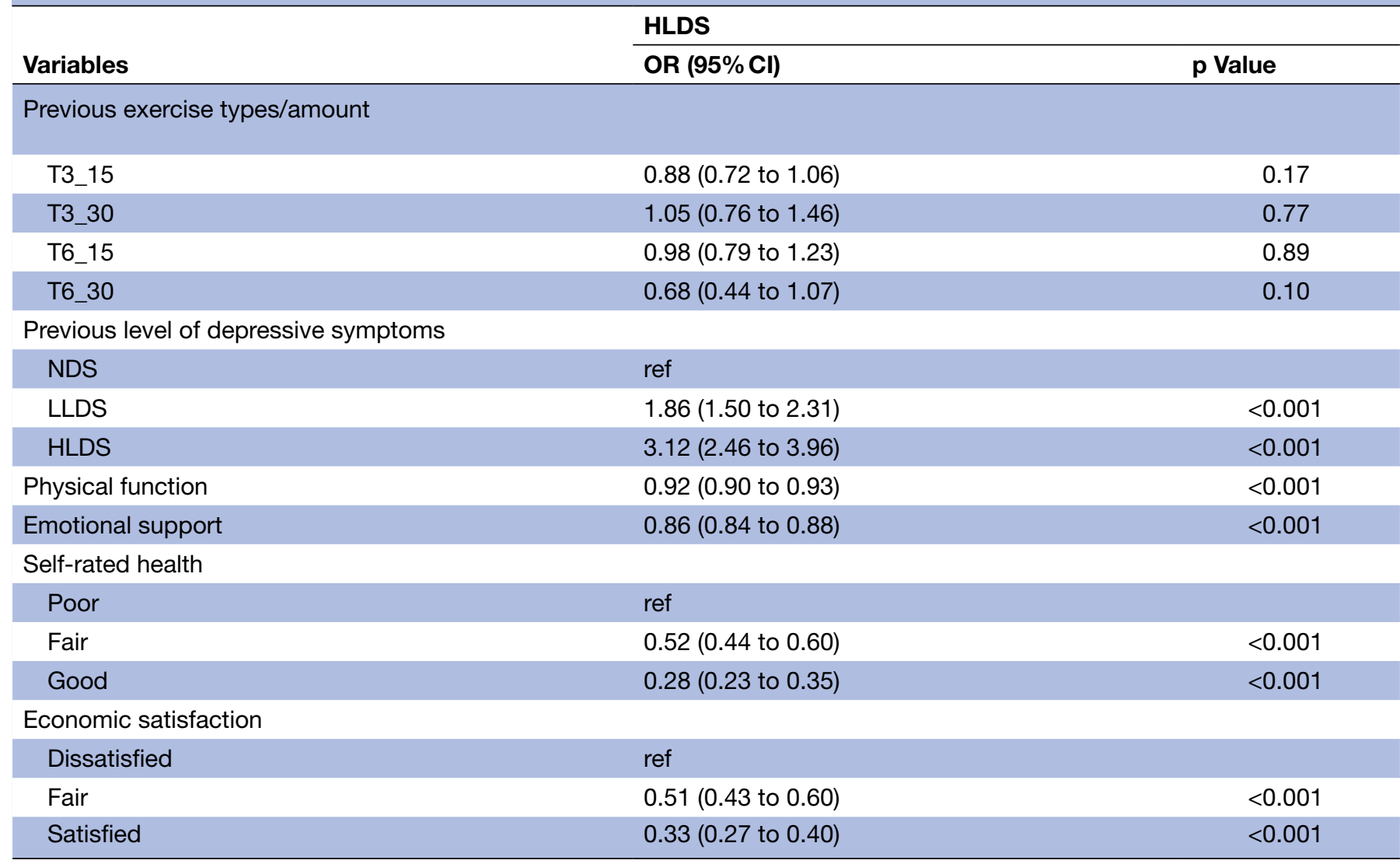

T3_15: Exercise $\geq$ moderate intensity, $\geq 3$ times/week, $\geq 15 \mathrm{~min} /$ time.

T3_30: Exercise $\geq$ moderate intensity, $\geq 3$ times/week, $\geq 30 \mathrm{~min} /$ time.

T6_15: Exercise $\geq$ moderate intensity, $\geq 6$ times/week, $\geq 15 \mathrm{~min} /$ time.

T6_30: Exercise $\geq$ moderate intensity, $\geq 6$ times/week, $\geq 30 \mathrm{~min} /$ time.

*All of the analysis models were adjusted according to present age, gender, education, marital status, smoking, social participation and chronic conditions including cancer, chronic respiratory disease, gastrointestinal, hypertension, diabetes mellitus, heart disease, stroke, arthritis, hepatobiliary disease and renal disease.

HLDS, higher level of depressive symptoms (CESD $\geqq 10)$; GLMM, generalised linear mixed models; LLDS, lower level of depressive symptoms;

NDS, no depressive symptom.

$2010 .{ }^{29}$ It is important to promote exercise, especially among older adults, who are more vulnerable to physical and psychological dysfunctions. The general recommendation for older adults is moderate intensity exercise accumulated to at least $30 \mathrm{~min}$ each day for at least 5 days a week to total $150-300 \mathrm{~min} /$ week, or vigorous intensity exercise at least 20-30 min per day for 3-5 days per week to total $75-100 \mathrm{~min} /$ week. $^{18}$ However, East Asians usually engage in fewer physical activities at lower intensity than people in western countries. ${ }^{30}{ }^{31}$ In consideration of physical conditions, it would be helpful to determine the minimal volume of exercise for older adults required to improve their health.

This study showed that the percentage of participants who engaged in exercise type T6_15 was higher than that of T3_30 and T6_30, which indicates that lower intensity, higher frequency exercise may be more acceptable to older people than higher intensity exercise at a lower frequency. Furthermore, the low-volume exercise type has been shown to have benefits related to reducing all-cause mortality and all-cancer mortality. ${ }^{19}{ }^{32}$ Therefore, based on the findings of our study, we feel confident about concluding that persistent low-amount exercise with the same moderate intensity (at least $\geq 15 \mathrm{~min} / 6$ times/week) may also benefit older adults both physically and psychologically.

Because of the social stigma of depressive symptoms, many people with this condition tend to remain undertreated. When unable to appropriately address the causes or when there is no access to adequate non-medical or community services to treat depression, patients may become further burdened due to a lack of solutions for specific conditions. ${ }^{33}$ Our study provides a practical and non-medical option to prevent higher levels of depressive symptoms. Most importantly, it will help reduce the unnecessary use of medication, which sometimes causes adverse drug reactions in older adults, and it may also help people when they lack awareness of their disorder or are reluctant to be treated.

Still, there are several other factors affecting depressive symptoms. Depression is significantly associated with chronic medical conditions, problems with activities of 


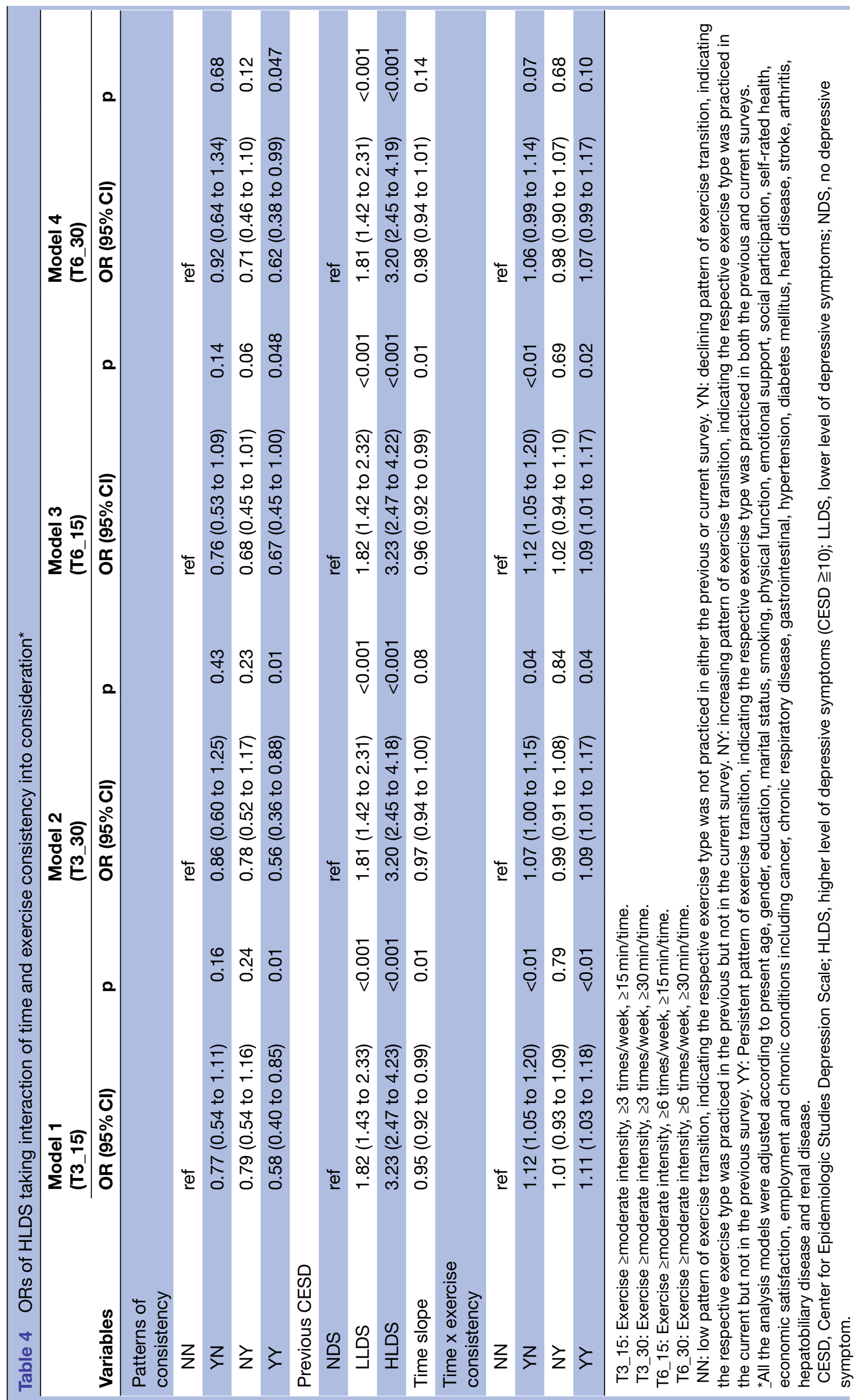


daily living (ADLs), poor social support and previous depressive conditions. ${ }^{74} 35$ Functional limitations and arthritis are among the strong risk factors in chronic conditions for depression. ${ }^{36}$ Physical function, emotional support, self-rated health and economic satisfaction were consistently shown to significantly influence HLDS in all analyses in our study. However, among the above-mentioned factors, exercise is the more changeable variable, which could also benefit physical function and self-rated health.

This is the first report to examine the impacts of four different types of exercise on depressive symptoms in the elderly according to the recommendations of different experts. ${ }^{19}$ However, there have been previous studies that have examined the relationship between physical activity and depressive symptoms in the elderly with different definitions of exercise groups in different areas (city/rural). ${ }^{37} 38$ Thus, to compare the results, the compatibility of participants, the exercise measurement and the categories of the exercise groups should be carefully considered. The advantages of this study include the fact that it included a nationally representative sample, a longitudinal cohort design, a test of different amount of exercise, an examination of the changes in exercise status over time and a proper consideration of statistical analysis methods.

Nonetheless, the study has some limitations. First, the observation for the outcome event was performed the same time as the second visit to develop the variables for transitional patterns of exercise, which may have reduced the interpretation of a causal relationship if the association between current exercise and the outcome event is too strong. However, if the assumption is true, the bias will support the null hypothesis. The results indicate that the significantly protective effects of a persistent pattern of exercise are consistent across all types of exercise considered in this study. The increasing exercise pattern did not result in the same finding, although both patterns indicated that the subjects had practiced the respective exercises on their second visit. We are therefore comfortable with inferring that a persistent pattern of exercise has more influence than increasing and other transitional patterns of exercise. Second, the effects of different variables for HLDS may be altered for different cohorts because of changes in medicine, antidepressants, nutrition or in the environment. This may limit the application of the findings of this study. Third, the measurement for physical activity did not include a timeframe but only asked participants 'Do you usually engage in exercise?' This may reduce the reliability of the measurement of exercise. However, most of the time, when a questionnaire does not mention a timeframe, it implies 'in the past year'. Lastly, ADLs were not included in the analysis because it may include those who cannot perform exercise. We used physical function ability, which has shown to be hierarchically associated with instrumental and basic $\mathrm{ADL}^{25}$ to control for any differences related to limitations in mobility.

\section{CONCLUSION}

Consistent exercise comprised of at least $15 \mathrm{~min}$ per time, three times a week of moderate intensity is significantly associated with lower risk of depressive symptoms. Increasing the frequency to more than five times per week will benefit older adults both physically and psychologically. We recommend taking this low amount of exercise into serious consideration when designing exercise programmes related to older adults.

Acknowledgements We would like to thank the Health Promotion Administration, Ministry of Health and Welfare of Taiwan for providing the dataset for analysis.

Contributors $\mathrm{Y}-\mathrm{CC}$ and $\mathrm{M}-\mathrm{CL}$ designed and conducted the study and wrote the daft; I-HH analysed the data and interpreted the tables; W-CIW conducted literature review and revised the draft; $\mathrm{SCH}$ advised the whole study and completed the manuscript. All authors contributed to the interpretation of results, critically reviewed the draft and approved the final manuscript.

Competing interests None declared.

Ethics approval Institutional Ethics Committee of Chia-Yi Christian Hospital (registry number 104040).

Provenance and peer review Not commissioned; externally peer reviewed. Data sharing statement No additional data are available.

Open Access This is an Open Access article distributed in accordance with the Creative Commons Attribution Non Commercial (CC BY-NC 4.0) license, which permits others to distribute, remix, adapt, build upon this work non-commercially, and license their derivative works on different terms, provided the original work is properly cited and the use is non-commercial. See: http://creativecommons.org/ licenses/by-nc/4.0/

(c) Article author(s) (or their employer(s) unless otherwise stated in the text of the article) 2017. All rights reserved. No commercial use is permitted unless otherwise expressly granted.

\section{REFERENCES}

1. Laborde-Lahoz P, El-Gabalawy R, Kinley J, et al. Subsyndromal depression among older adults in the USA: prevalence, comorbidity, and risk for new-onset psychiatric disorders in late life. Int J Geriatr Psychiatry 2015;30:677-85.

2. Chong MY, Tsang HY, Chen CS, et al. Community study of depression in old age in Taiwan: prevalence, life events and sociodemographic correlates. Br J Psychiatry 2001;178:29-35.

3. Global, regional, and national incidence, prevalence, and years lived with disability for 301 acute and chronic diseases and injuries in 188 countries, 1990-2013: a systematic analysis for the Global Burden of Disease Study 2013. Lancet 2015;386:743-800.

4. Chang YC, Yao G, Hu SC, , et al. Depression Affects the Scores of All Facets of the WHOQOL-BREF and May Mediate the Effects of Physical Disability among Community-Dwelling Older Adults. PLoS One 2015;10:e0128356.

5. Webb E, Blane D, McMunn A, et al. Proximal predictors of change in quality of life at older ages. J Epidemiol Community Health 2011;65:542-7.

6. Garin N, Olaya B, Moneta MV, et al. Impact of multimorbidity on disability and quality of life in the Spanish older population. PLOS One 2014;9:e111498.

7. Schoevers RA, Beekman AT, Deeg DJ, et al. Risk factors for depression in later life; results of a prospective community based study (AMSTEL). J Affect Disord 2000;59:127-37.

8. Veerman JL, Shrestha RN, Mihalopoulos C, et al. Depression prevention, labour force participation and income of older working aged Australians: A microsimulation economic analysis. Aust $N Z \mathrm{~J}$ Psychiatry 2015;49:430-6.

9. Lee SY, Franchetti MK, Imanbayev A, et al. Non-pharmacological prevention of major depression among community-dwelling older adults: a systematic review of the efficacy of psychotherapy interventions. Arch Gerontol Geriatr 2012;55:522-9.

10. Forsman AK, Schierenbeck I, Wahlbeck K. Psychosocial interventions for the prevention of depression in older adults: systematic review and meta-analysis. J Aging Health 2011;23:387-416. 
11. Stahl ST, Albert SM, Dew MA, et al. Coaching in healthy dietary practices in at-risk older adults: a case of indicated depression prevention. Am J Psychiatry 2014;171:499-505.

12. Tipton CM. The history of "Exercise Is Medicine" in ancient civilizations. Adv Physiol Educ 2014;38:109-17.

13. Rethorst CD, Wipfli BM, Landers DM. The antidepressive effects of exercise: a meta-analysis of randomized trials. Sports Med 2009;39:491-511.

14. Brenes GA, Williamson JD, Messier SP, et al. Treatment of minor depression in older adults: a pilot study comparing sertraline and exercise. Aging Ment Health 2007;11:61-8.

15. Cooney GM, Dwan K, Greig CA, et al. Exercise for depression. Cochrane Database Syst Rev 2013;9:CD004366.

16. Walker JG, Mackinnon AJ, Batterham P, et al. Mental health literacy, folic acid and vitamin B12, and physical activity for the prevention of depression in older adults: randomised controlled trial. $\mathrm{Br} \mathrm{J}$ Psychiatry 2010;197:45-54.

17. Rhyner KT, Watts A. Exercise and Depressive Symptoms in Older Adults: A Systematic Meta-Analytic Review. J Aging Phys Act 2016;24:234-46.

18. Pescatello LS. ACSM's Guidelines for Exercise Testing and Prescription. 9th Edition: American College of Sports Medicine, 2013.

19. Wen CP, Wai JP, Tsai MK, et al. Minimum amount of physical activity for reduced mortality and extended life expectancy: a prospective cohort study. Lancet 2011;378:1244-53.

20. Radloff LS. The CES-D Scale: A Self-Report Depression Scale for Research in the General Population. Appl Psychol Meas 1977;1-385-401.

21. Kohout FJ, Berkman LF, Evans DA, et al. Two shorter forms of the CES-D (Center for Epidemiological Studies Depression) depression symptoms index. J Aging Health 1993;5:179-93.

22. Björgvinsson T, Kertz SJ, Bigda-Peyton JS, et al. Psychometric properties of the CES-D-10 in a psychiatric sample. Assessment 2013;20:429-36.

23. Lyness JM, Chapman BP, McGriff J, et al. One-year outcomes of minor and subsyndromal depression in older primary care patients. Int Psychogeriatr 2009;21:60-8.

24. Chang YC, Ouyang WC, Lu MC, et al. Levels of depressive symptoms may modify the relationship between the WHOQOL-BREF and its determining factors in community-dwelling older adults. Int Psychogeriatr 2016;28:591-601.
25. Chen HY, Wang CY, Lee MY, et al. A hierarchical categorisation of tasks in mobility disability. Disabil Rehabil 2010;32:1586-93.

26. Ku PW, Fox KR, Chen LJ, et al. Physical activity and depressive symptoms in older adults: 11-year follow-up. Am J Prev Med 2012;42:355-62.

27. Ku PW, Fox KR, Chen LJ. Physical activity and depressive symptoms in Taiwanese older adults: a seven-year follow-up study. Prev Med 2009;48:250-5

28. Chen LJ, Stevinson C, Ku PW, et al. Relationships of leisure-time and non-leisure-time physical activity with depressive symptoms: a population-based study of Taiwanese older adults. Int J Behav Nutr Phys Act 2012;9:28.

29. Lim SS, Vos T, Flaxman AD, et al. A comparative risk assessment of burden of disease and injury attributable to 67 risk factors and risk factor clusters in 21 regions, 1990-2010: a systematic analysis for the Global Burden of Disease Study 2010. Lancet 2012;380:2224-60.

30. Ku PW, Fox KR, McKenna J, et al. Prevalence of leisure-time physical activity in Taiwanese adults: results of four national surveys, 2000-2004. Prev Med 2006;43:454-7.

31. Wai JP, Wen CP, Chan HT, et al. Assessing physical activity in an Asian country: low energy expenditure and exercise frequency among adults in Taiwan. Asia Pac J Clin Nutr 2008;17:297-308.

32. Hubbard RE, Fallah N, Searle SD, et al. Impact of exercise in community-dwelling older adults. PLoS One 2009;4:e6174.

33. Bird MJ, Parslow RA. Potential for community programs to prevent depression in older people. Med J Aust 2002;177 Suppl:S107-10.

34. Schoevers RA, Geerlings MI, Beekman AT, et al. Association of depression and gender with mortality in old age. Results from the Amsterdam Study of the Elderly (AMSTEL). Br J Psychiatry 2000;177:336-42.

35. Roberts RE, Kaplan GA, Shema SJ, et al. Does growing old increase the risk for depression? Am J Psychiatry 1997;154:1384-90.

36. Dunlop DD, Lyons JS, Manheim LM, et al. Arthritis and heart disease as risk factors for major depression: the role of functional limitation. Med Care 2004;42:502-11.

37. Lampinen P, Heikkinen E. Reduced mobility and physical activity as predictors of depressive symptoms among community-dwelling older adults: an eight-year follow-up study. Aging Clin Exp Res 2003;15:205-11.

38. Yoshida $\mathrm{Y}$, Iwasa $\mathrm{H}$, Kumagai $\mathrm{S}$, et al. Longitudinal association between habitual physical activity and depressive symptoms in older people. Psychiatry Clin Neurosci 2015;69:686-92. 